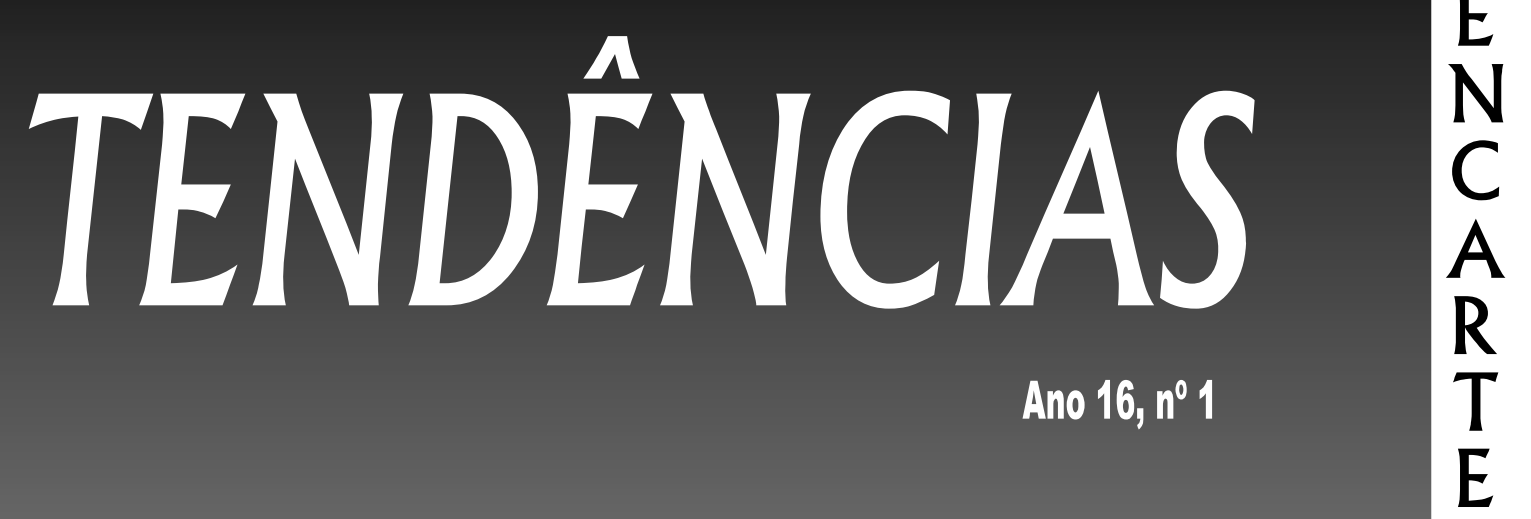

D

A

$R$
E
V
I
S
$\mathrm{T}$
$\mathrm{A}$

D

$\mathrm{O}$

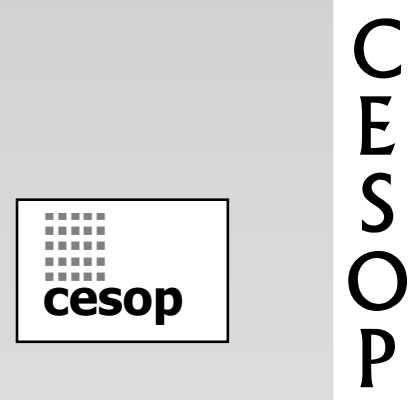

OPINIÃO PÚBlICA, Campinas, Vol. 16, n 1, Junho, 2010, Encarte Tendências. p.251-267 
Este Encarte Tendências traz dados da pesquisa nacional $\boldsymbol{A}$ desconfiança dos cidadãos nas instituições democráticas. Realizada em junho de 2006 e coordenada pelos professores José Álvaro Moisés (USP) e Rachel Meneguello (UNICAMP), esta pesquisa orientou-se pela preocupação com o fenômeno da confiança política na democracia contemporânea e procurou contribuir para explicar o cenário de paradoxo que caracteriza a relativamente consolidada democracia brasileira na qual persiste a ampla desconfiança nas instituições democráticas.

As instituições democráticas investigadas foram, em primeiro lugar, a própria comunidade política de que fazem parte os cidadãos como fator de identificação e de integração política, assim como as concepções sobre cidadania e sobre direitos civis e políticos; também foram abordadas as instituições de representação, como o Congresso Nacional e os partidos; os órgãos de execução de políticas públicas como a presidência da República, os ministérios, as forças armadas, as agências de serviços públicos e, finalmente, o Supremo Tribunal Federal e demais organismos do poder judiciário. O estudo das instituições privadas como a família, as corporações e outras organizações da sociedade civil deu-se a partir de sua função de contraponto do funcionamento das instituições democráticas, isto é, como parte do capital social a partir do qual a participação política é referida às instituições públicas.

Em linhas gerais, a confiança foi abordada como medida da distância entre os cidadãos e o regime democrático, seja como resultado de ações ou políticas em sentido amplo, bem como resultado de processos políticos e experiências cotidianas, tais como a relação com os serviços públicos.

Neste Encarte são apresentados alguns dados que ilustram as dimensões centrais da pesquisa, como as noções de cidadania, direitos e a percepção sobre a intervenção dos cidadãos na esfera política; o papel do Estado e a confiança nos órgãos públicos; percepções sobre a corrupção, práticas ilegais na política e na gestão pública; dados gerais sobre a confiança nas instituições, e as percepções sobre o desempenho de governos ao longo do tempo, especificamente os últimos governos da ditadura militar, os dois mandatos do governo $\mathrm{FHC}$ e o primeiro mandato do governo Lula.

A pesquisa $\boldsymbol{A}$ desconfiança dos cidadãos nas instituições democráticas foi desenvolvida no âmbito do Projeto Temático FAPESP entre 2005 e 2009, e contou com a participação de pesquisadores e alunos de graduação e pós-graduação associados ao NUPPS - Núcleo de Pesquisa de Políticas Públicas da USP e ao CESOP - Centro de Estudos de Opinião Pública da UNICAMP. As informações do survey encontram-se na ficha técnica do Encarte. 
A pesquisa buscou identificar as noções gerais dos indivíduos quanto à cidadania. Os dados apontam a dimensão legal institucional como a mais presente no conjunto de referências dos entrevistados. Em seguida, a dimensão moral emerge como a segunda mais importante, na qual constam a honestidade e o caráter.

\section{O que é ser cidadão?}

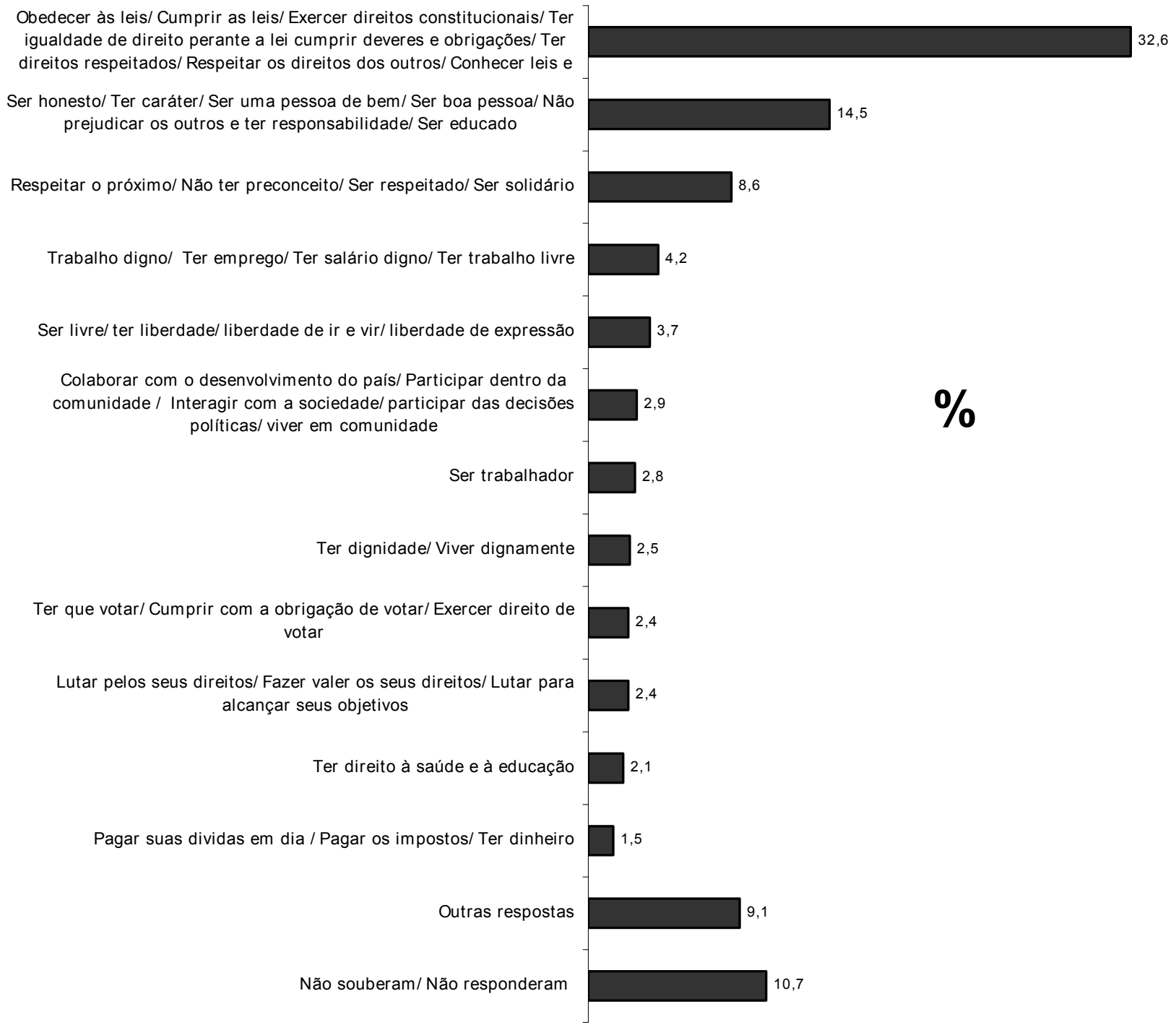




\section{Todos os brasileiros têm iguais oportunidades de acesso à justiça?}

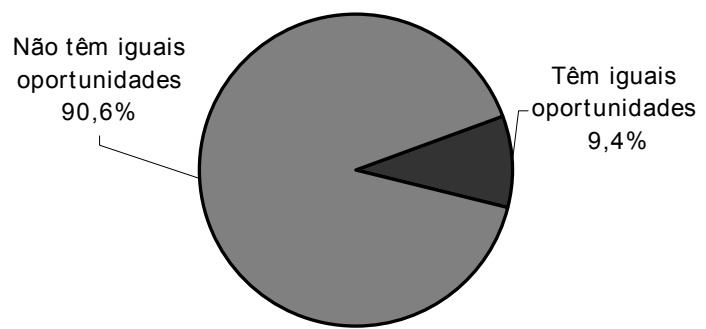

Pergunta: Tem gente que acha que todos os brasileiros têm iguais oportunidades de acesso à justiça. Outros acham que nem todos os brasileiros têm iguais oportunidades de acesso à justiça .O que você acha?

\section{Os brasileiros são conscientes de suas obrigaçôes?}

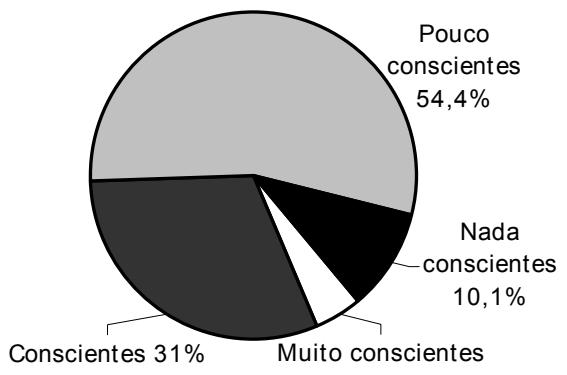

$4,6 \%$

Pergunta: Você diria que os brasileiros são muito conscientes,

\section{Os brasileiros são conscientes de seus direitos?}

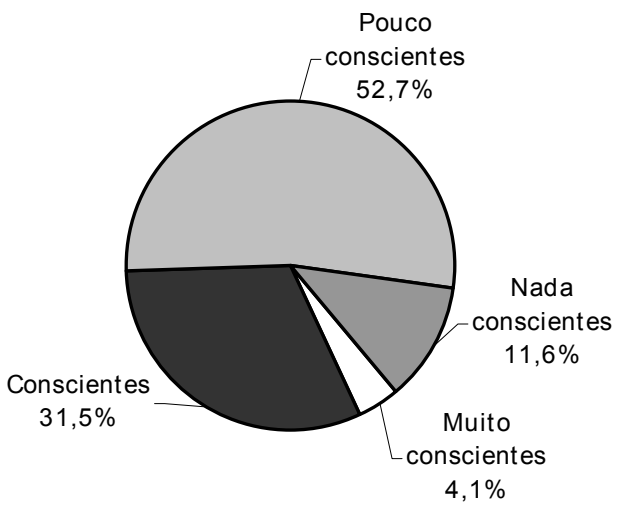

Pergunta: E dos seus direitos? Você diria que os brasileiros são muito conscientes, conscientes, pouco conscientes ou nada conscientes de seus direitos?

\section{Há igualdade perante a lei no Brasil?}

Não há igualdade perante a lei $81 \%$

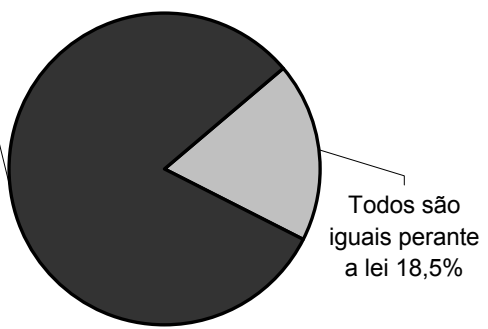

Pergunta: A Constituição brasileira estabelece que todos os brasileiros são iguais perante a lei. Você acha que todos são iguais perante a lei ou que não há igualdade perante a lei no Brasil?

\section{"A lei deve ser obedecida sempre, qualquer que seja a circunstância".}

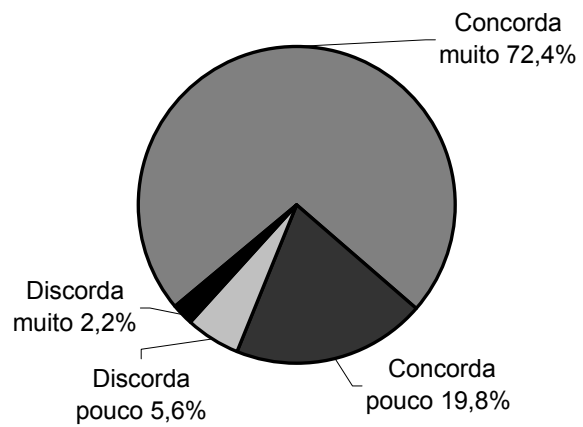

Pergunta: Por favor, diga se você concorda ou discorda da seguinte afirmação: "A lei deve ser obedecida sempre, qualquer que seja a circunstância."

\section{Os brasileiros conseguem fazer valer seus direitos?}

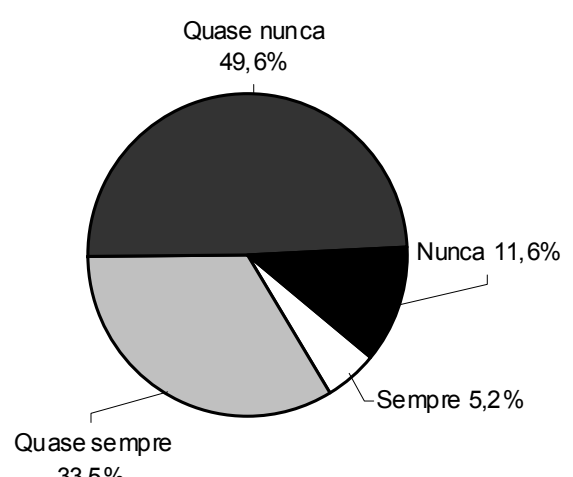

$33,5 \%$

Pergunta: Pensando em como funcionam as coisas no Brasil, Você diria que na prática, os brasileiros conseguem fazer valer os seus direitos sempre, quase sempre, quase nunca ou nunca? 
Os brasileiros exigem seus direitos?

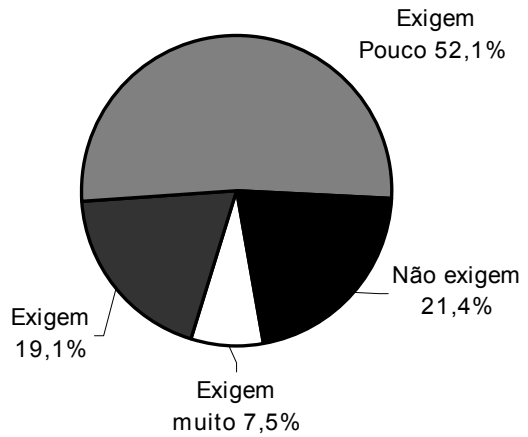

Pergunta: Você diria que os brasileiros exigem os seus direitos? Exigem muito, apenas exigem, exigem pouco ou não exigem seus direitos?

\section{Os brasileiros cumprem as leis?}

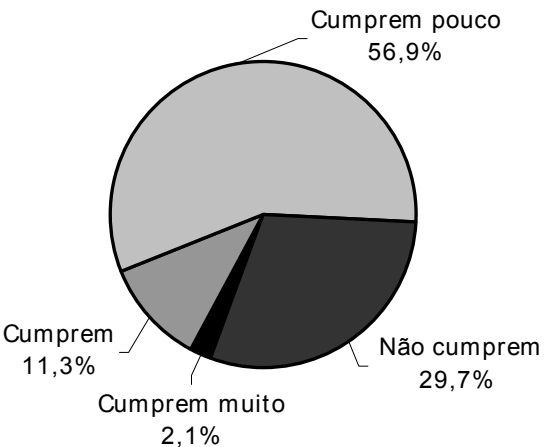

Pergunta: Você diria que os brasileiros... as leis ?

\section{Direitos mais importantes para os cidadãos}

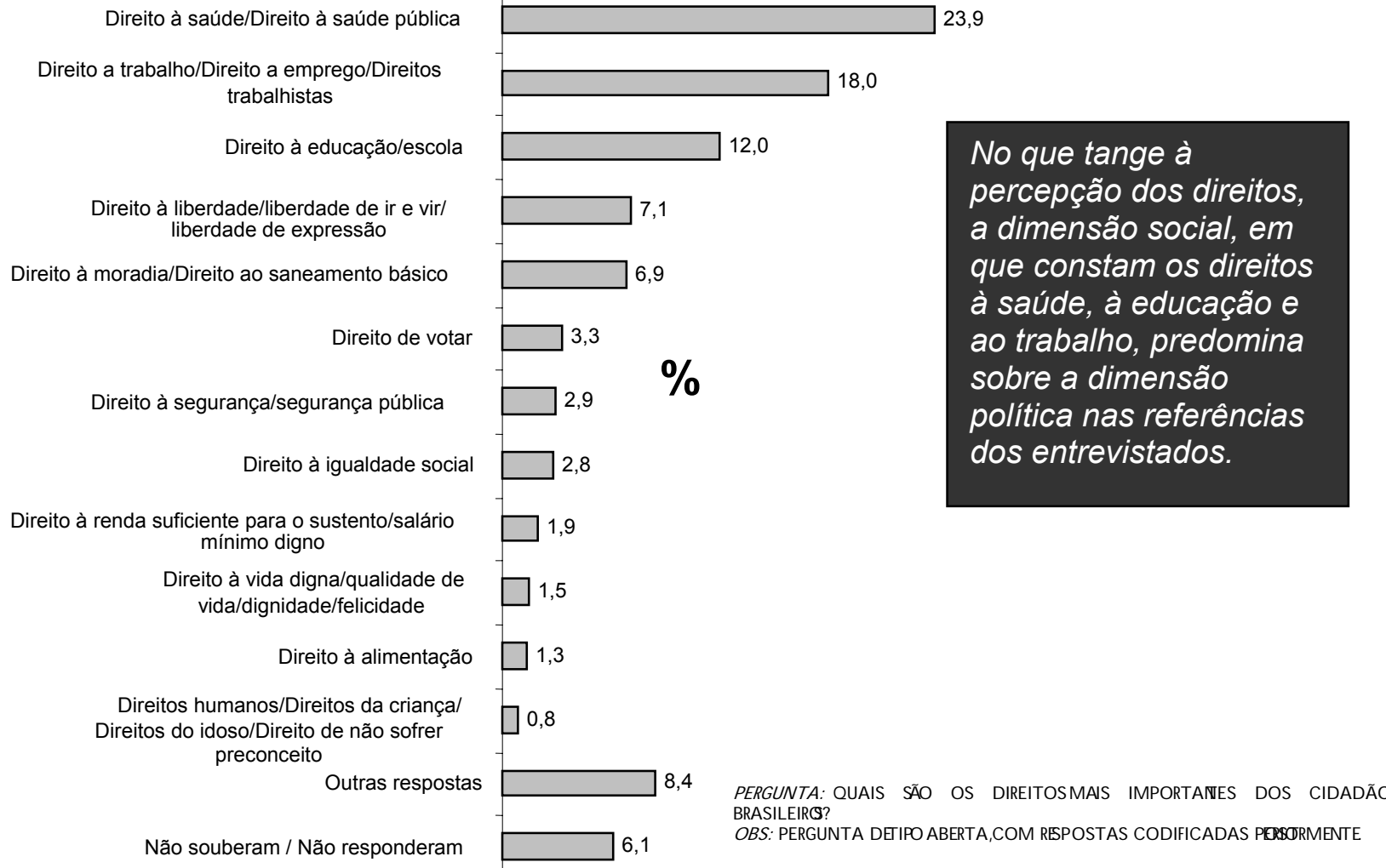

Embora o direito de voto tenha lugar menos destacado entre os direitos mais importantes - como mostram as respostas do gráfico acima - quando perguntados sobre a importância de votar, ela é mencionada por mais da metade dos entrevistados, como mostra o gráfico da página seguinte. No entanto, é significativa a distância que os cidadãos têm com relação ao sistema político. É isso o que indicam as opiniões que afirmam a política como uma coisa complicada e a idéia de que cidadãos comuns têm pequena influência sobre as decisões de governo - como também mostram os gráficos da página seguinte.

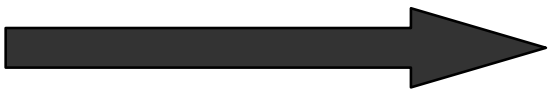




\section{Sobre a importância de votar}

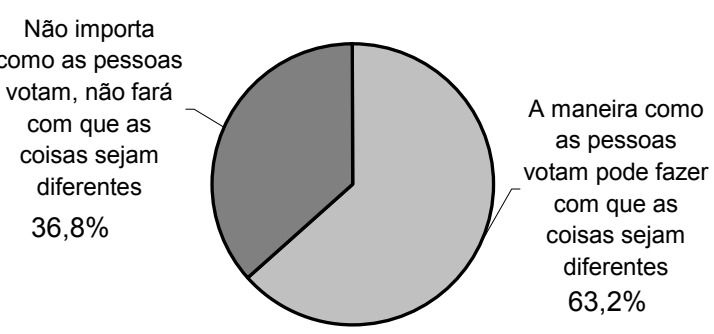

Pergunta: Você acha que: seu voto faz a diferença?

\section{"Os funcionários do governo não} se preocupam muito com aquilo que pessoas como você pensam"

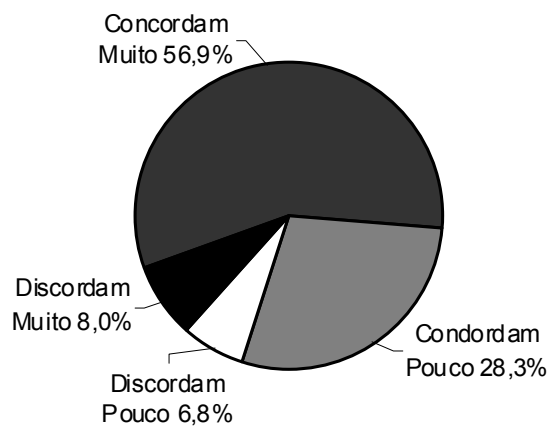

Pergunta: Vou ler algumas frases sobre política e gostaria de saber se você...: Concorda muito, concorda pouco, discorda muito, discorda pouco.

"O voto permite que pessoas como você possam influenciar nos acontecimentos do país"

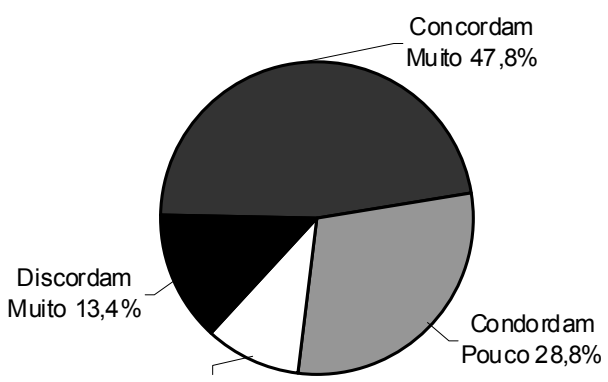

Discordam Pouco $10,0 \%$

Pergunta: Vou ler algumas frases sobre política e gostaria de saber se você ...: Concorda muito, concorda pouco, discorda muito, discorda pouco.

\section{As eleições no Brasil são limpas?}

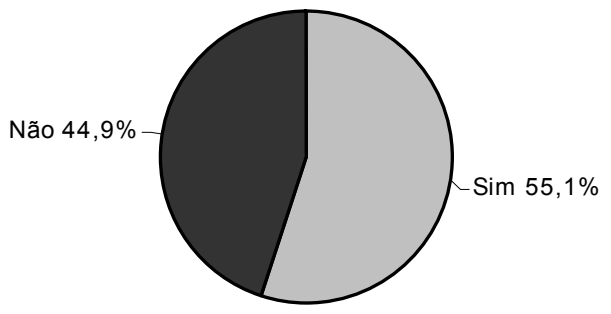

Pergunta: Você acredita que as eleições no Brasil são limpas ou são objeto de fraude?

"Às vezes, a política e o governo parecem tão complicados que uma pessoa como você não pode realmente entender o que está acontecendo" Discordam

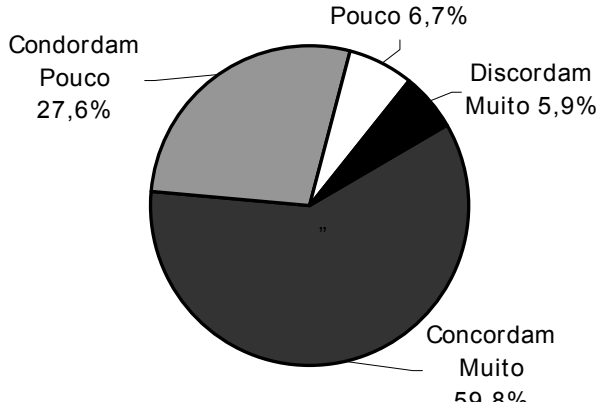

Pergunta: Vou ler algumas frases sobre política e gostaria de saber se você ...: Concorda muito, concorda pouco, discorda muito, discorda pouco...

\section{"Pessoas como você não têm como influenciar no que $o$ governo faz"}

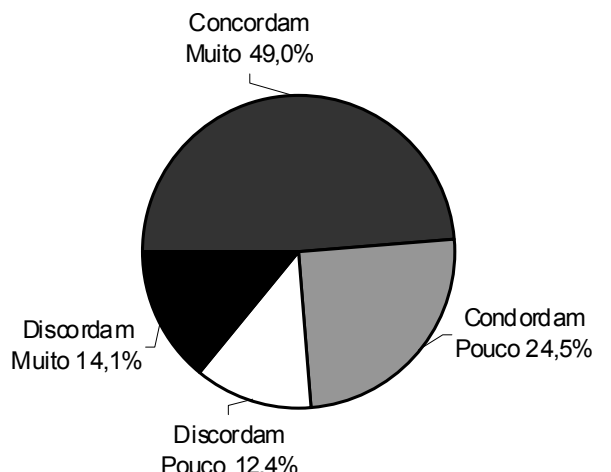

Pergunta: Vou ler algumas frases sobre política e gostaria de saber se você ...: Concorda muito, concorda pouco, discorda muito, discorda pouco. 
Os dados sobre confiança institucional mostram que, embora as instituições sejam consideradas necessárias ao funcionamento do sistema, há um claro déficit na relação entre os cidadãos e as intermediações dessa relação política. Há uma significativa confiança nas leis do país e no poder judiciário, contrastando com a baixa confiança nas instituições representativas.

\section{Confiança nas instituições públicas}

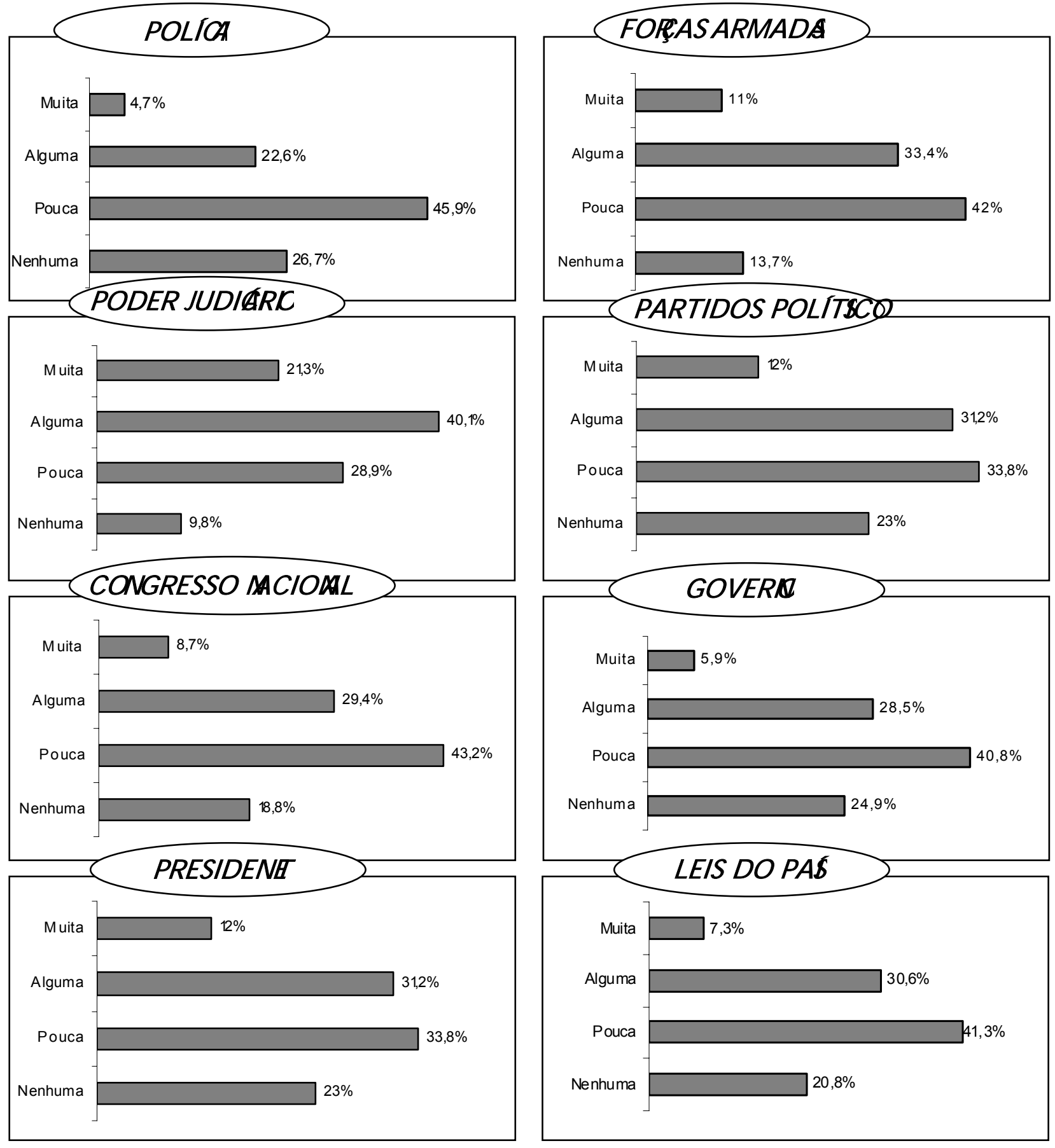

Pergunta: Vou citar alguns órgãos públicos e particulares e gostaria de saber qual é o grau de confiança que você tem em cada um deles: 
No conjunto de instituições públicas investigadas, a presidência da república se destaca como o órgão mais necessário ao funcionamento do país, na opinião dos entrevistados. Essa percepção corrobora as afirmações que apontam a forte preferência dos cidadãos pelo presidencialismo, assim como corrobora as avaliações negativas sobre políticos e partidos.

\section{Órgãos públicos necessários para o país seguir em frente}

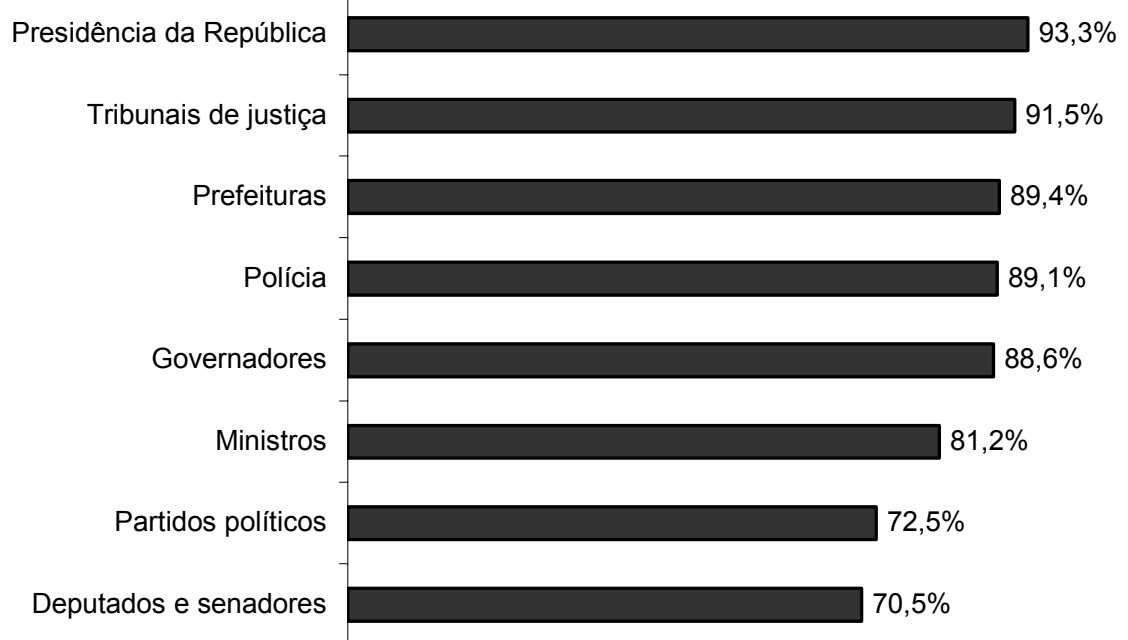

Pergunta: Vou ler uma lista de órgãos públicos como policia e escola e quero que você diga quais têm que ter para o país ir em frente:

\section{O órgão público mais importante para o país seguir em frente}

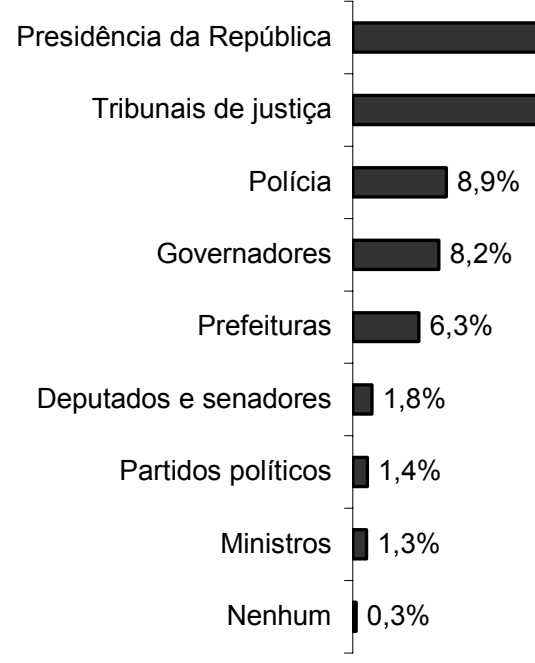

$52,6 \%$

$19,3 \%$

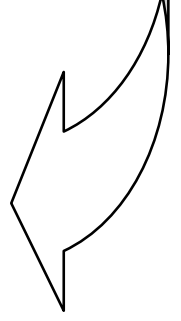

Pergunta: E qual desses é o mais importante?

A confiança nos órgãos públicos está claramente associada ao tratamento que os indivíduos recebem dela. $O$ tratamento igual, a eficiência nas respostas e no trabalho oferecido são aspectos básicos mencionados pelos entrevistados. 


\section{Requisitos para a confiança nos órgãos públicos, segundo os entrevistados da pesquisa}

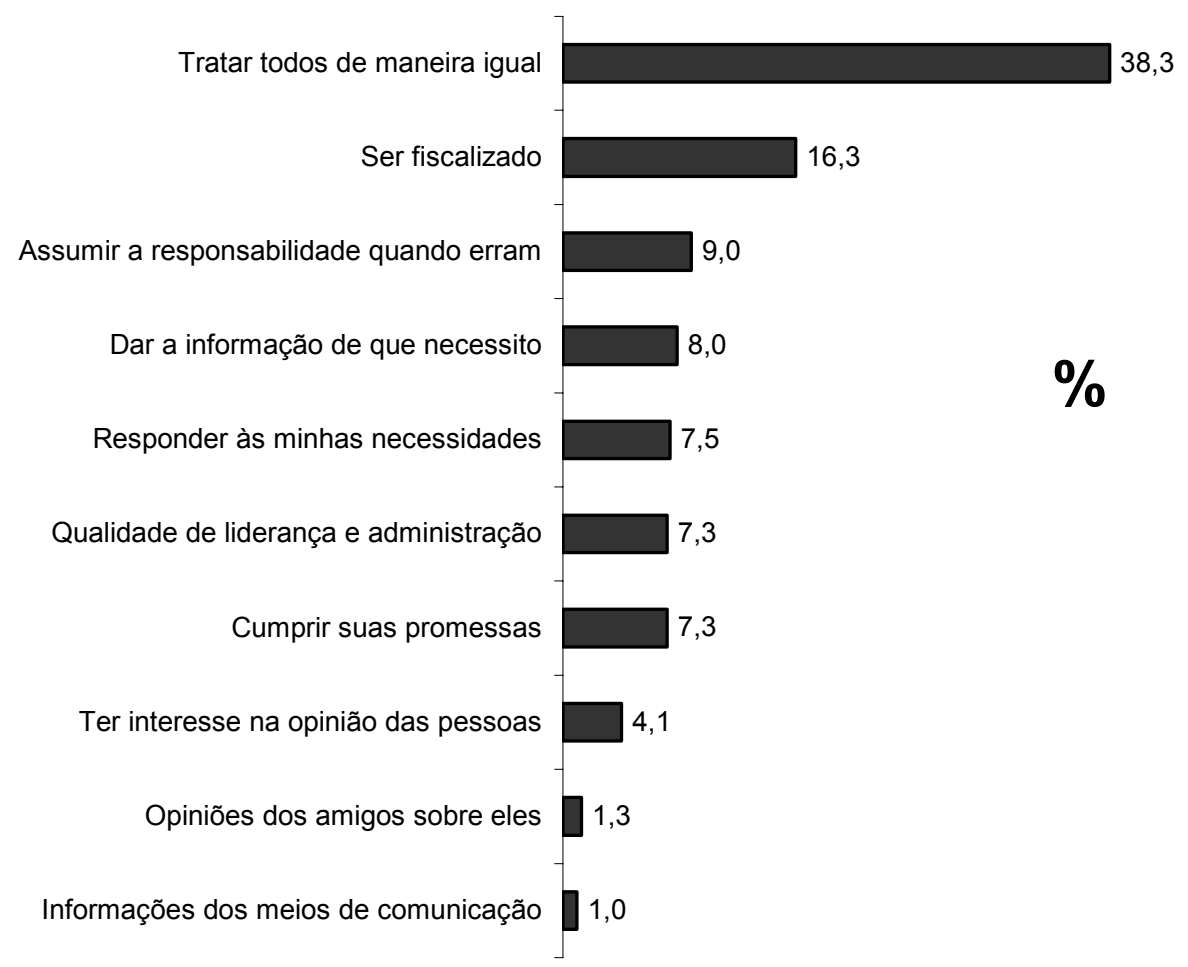

Pergunta: O que é importante para você confiar nos órgãos públicos? Qual é o mais importante: PRIMEIRO LUGAR

Com esses referenciais em mente, a avaliação geral sobre os órgãos públicos é predominantemente negativa, assim como é a percepção sobre o uso dos impostos pelo Estado. 


\section{Opiniões dos entrevistados sobre os órgãos públicos}

\section{(Apenas respostas "concorda muito" + "concorda pouco")}

Os órgãos públicos não se interessam pela opinião do usuário

As autoridades e dirigentes dos órgãos públicos são de baixa qualidade

Os meios de comunicação trasmitem muita informação negativa sobre os órgãos públicos

Os órgãos públicos não prestam informação sobre os serviços que fornecem

Os funcionários dos órgãos públicos tratam bem as pessoas

Meus amigos e familiares falam bem dos órgãos públicos

As atividades dos órgãos públicos são totalmente fiscalizadas

Os órgãos públicos tratam todas as pessoas igualmente

Os órgãos públicos cumprem suas promessas

Os órgãos públicos sempre assumem sua responsabilidade quando erram

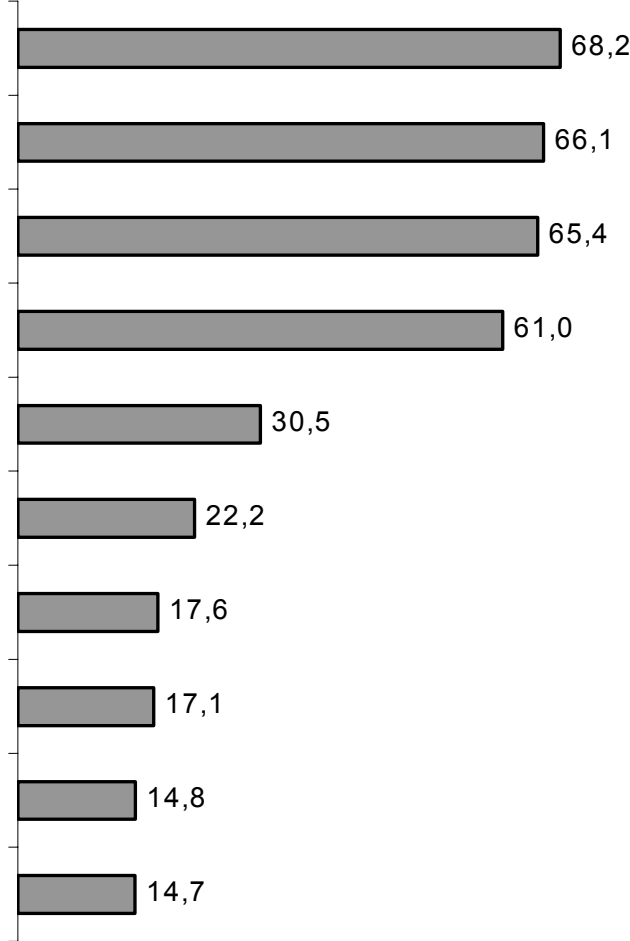

\section{O dinheiro dos impostos é bem gasto pelo} Estado?

Não 92,5

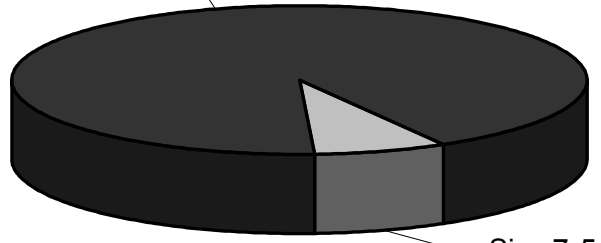

$\operatorname{Sim} 7,5$

Pergunta: A respeito dos impostos que os brasileiros pagam ao governo, você acha que o dinheiro dos impostos é bem gasto pelo Estado? 
As opiniões sobre o papel do Estado no funcionamento do país indicam certa preferência pela intervenção na economia e oferta de serviços, bem como na definição de políticas voltadas para diminuição de desigualdades sociais.

\section{Opiniões sobre o papel do Estado e do mercado \\ (Apenas respostas "concorda muito" + "concorda pouco")}

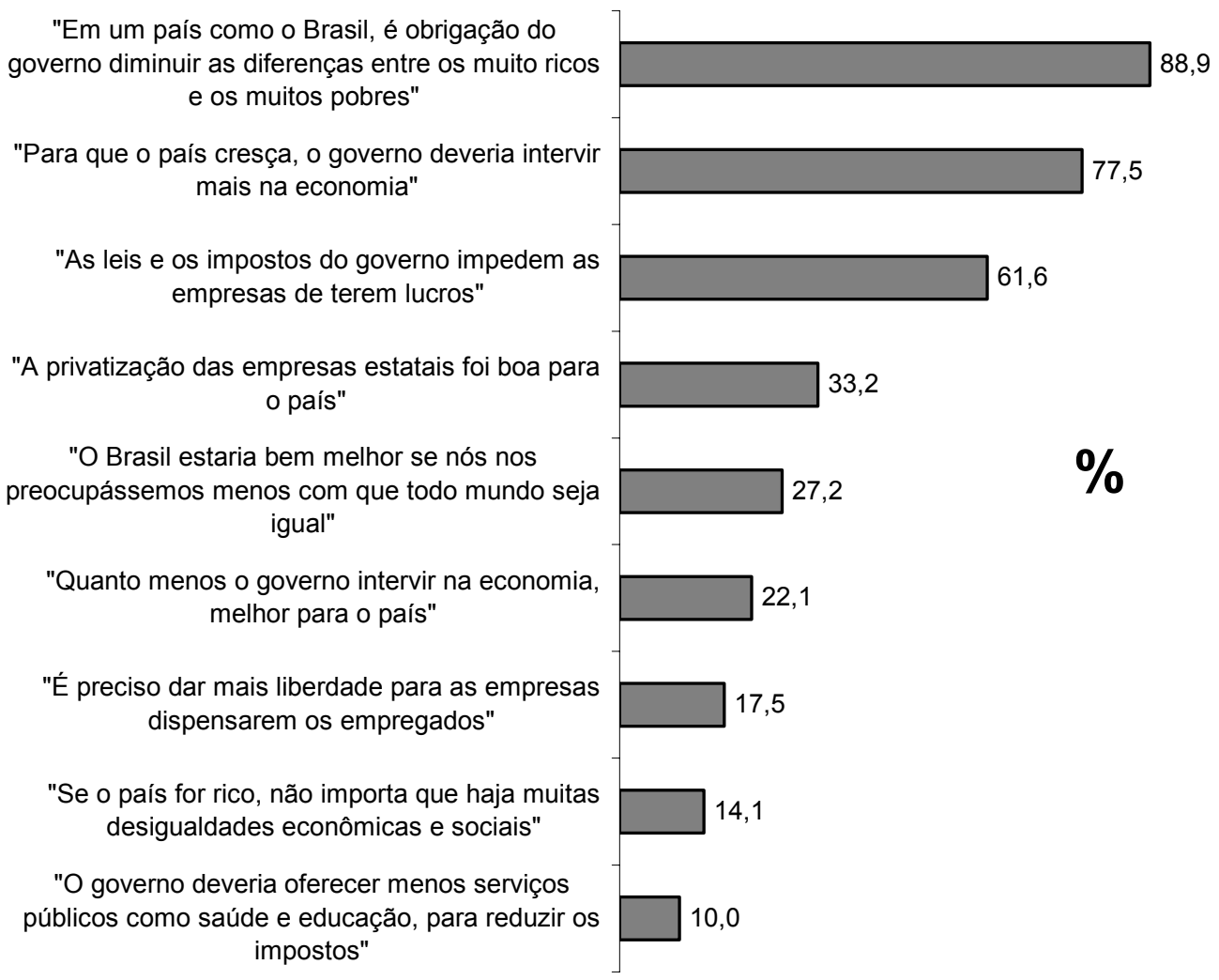

Pergunta: Agora vou ler para você mais uma série de frases e gostaria que você dissesse se concorda muito; concorda pouco; discorda pouco; discorda muito; nem concorda nem discorda. 


\section{Comparação entre governos}

A pesquisa procurou investigar os referenciais de avaliação de desempenho do regime através da comparação entre os últimos governos militares e os governos de FHC e de LULA quanto aos direitos humanos, à corrupção e o tráfico de influência e à economia. Os dados gerais mostram uma leve percepção de melhora nos governos democráticos para as três dimensões.
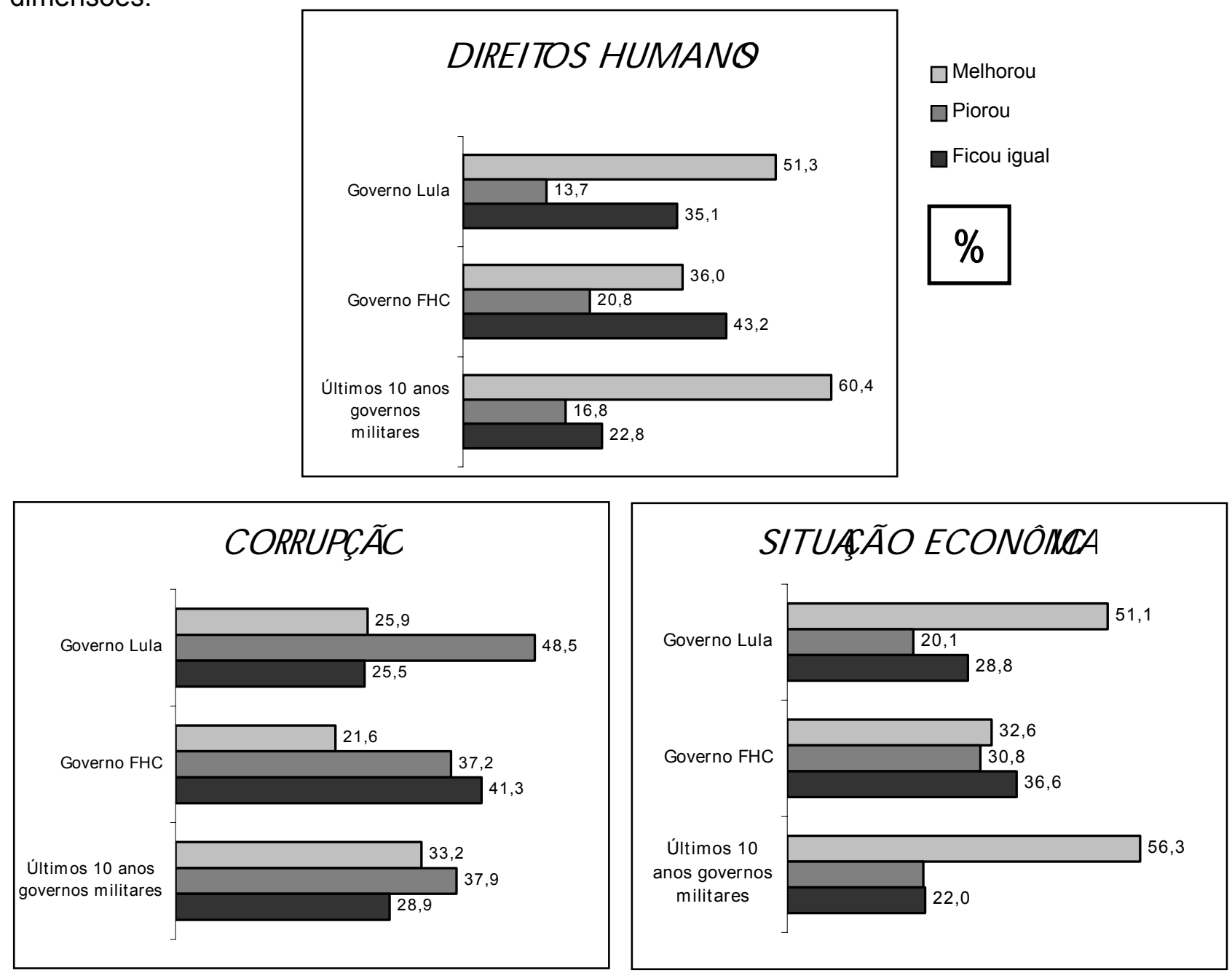

Perguntas: E quanto à situação econômica/ direitos humanos/corrupção e tráfico de influência no governo Lula - desde janeiro de 2003 - você diria que a situação econômica do país melhorou, piorou ou ficou igual ao que era antes?/ E durante o governo Fernando Henrique - entre janeiro de 1994 e dezembro de 2002 - você diria que a situação econômica do país melhorou, piorou ou ficou igual em relação ao que era antes?/ E em comparação com os últimos 10 anos dos governos militares, no tempo dos generais Geisel e Figueiredo, você diria que a situação econômica atual melhorou, piorou ou ficou igual ao que era antes? 


\section{Opiniões sobre o comportamento dos POLÍTICOS e GOVERNANTES BRASILEIROS}

Os dados sobre as percepções da corrupção política apontam os baixos índices de confiança nos políticos, assim como nas pessoas em geral. Os entrevistados consideram-se de forma mais positiva moralmente, e condenam, na sua maioria, as práticas ilegais e irregularidades na gestão pública.

\section{MUDAR DE PARTIDO EM TROCA DE DINHEIRO OU CARGO}

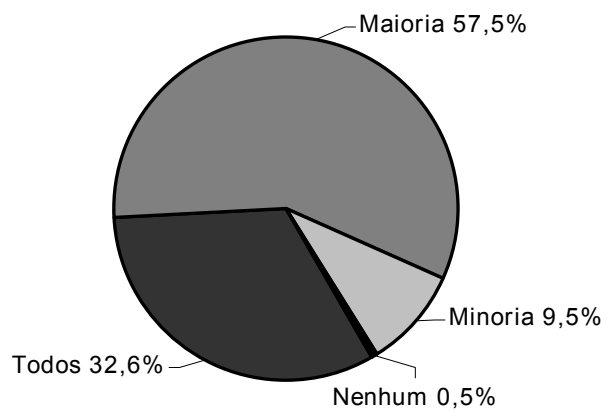

Pergunta: Em relação aos nossos políticos e governantes, o(a) sr(a) diria que é um comportamento ... dos políticos e governantes brasileiros: da maioria, da minoria, de todos, ou nenhum...
SUPERFATURAR OBRAS PÚBLICASE DESVIAR O DINHEIRO PARA O PATRIMÔNIO PESSOAL/ FAMILIAR DO POLÍTICO

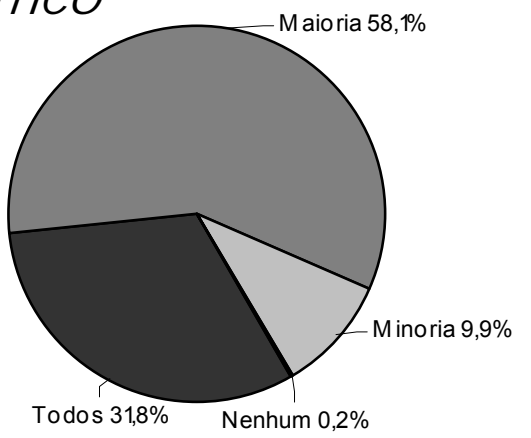

Pergunta: Em relação aos nossos políticos e governantes, o(a) sr(a) diria que é um comportamento ... dos políticos e governantes brasileiros: da maioria, da minoria, de todos, ou nenhum...

USAR "CAIXA 2" EM CAMPANHAS ELEITORAIS

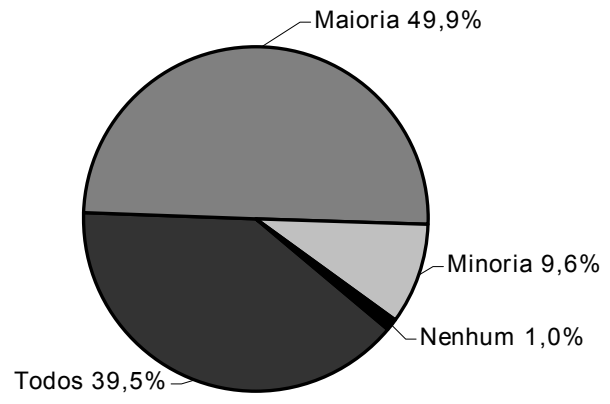

Pergunta: "Em relação aos nossos políticos e governantes, o(a) sr(a) diria que é um comportamento ... dos políticos e governantes brasileiros: da maioria, da minoria, de todos, ou nenhum... 


\section{Opiniões sobre o comportamento dos demais CIDADÃOS BRASILEIROS, se eles estivessem no lugar dos políticos}

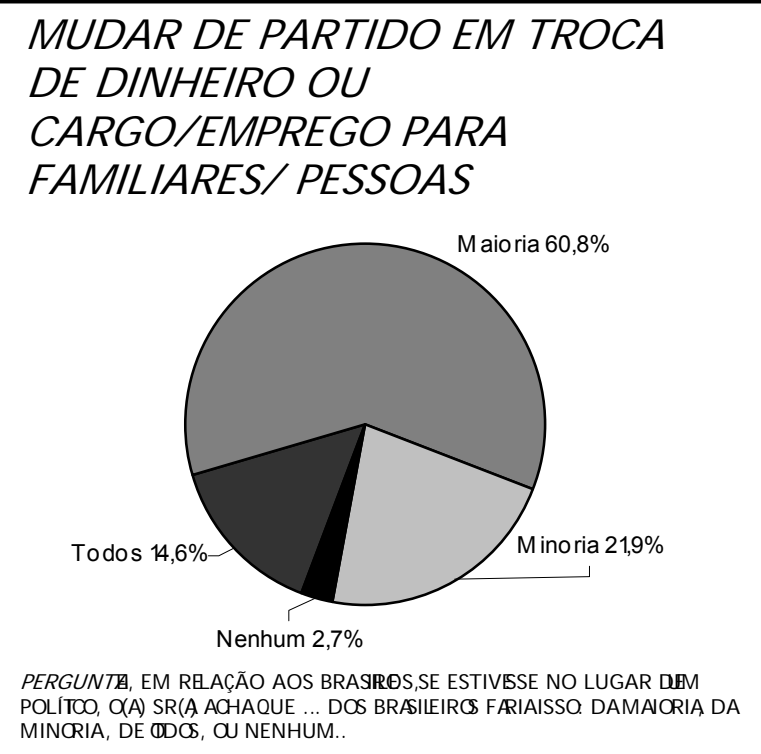

USAR "CAIXA 2"EM CAMPANHAS ELEITORAIS

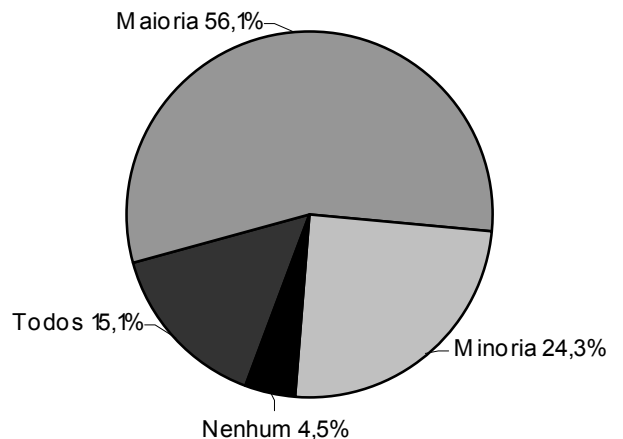

Pergunta: E, em relação aos brasileiros, se estivesse no lugar de um político, o(a) sr(a) acha que ... Dos brasileiros faria isso: da maioria, da minoria, de todos, ou nenhum...
SUPERFATURAR OBRAS PÚBLICASE DESVIAR O DINHEIRO PARA O PATRIMÔNIO PESSOAL/ FAMILIAR DO POLÍTICO

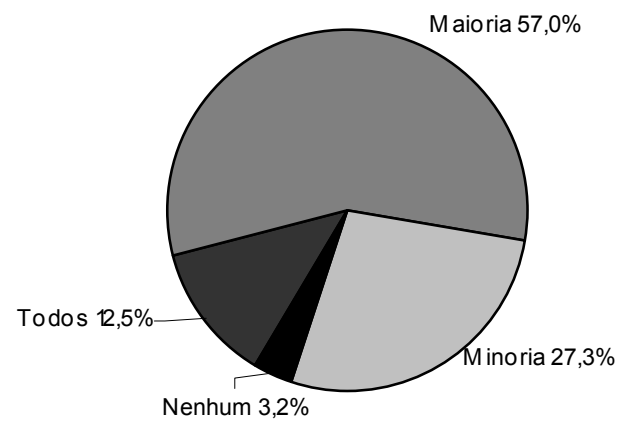

Pergunta: E, em relação aos brasileiros, se estivesse no lugar de um político, o(a) sr(a) acha que ... Dos brasileiros faria isso: da maioria, da minoria, de todos, ou nenhum... 


\section{Opiniões sobre o comportamento do PRÓPRIO ENTREVISTADO, se ele estivesse no lugar de um político}

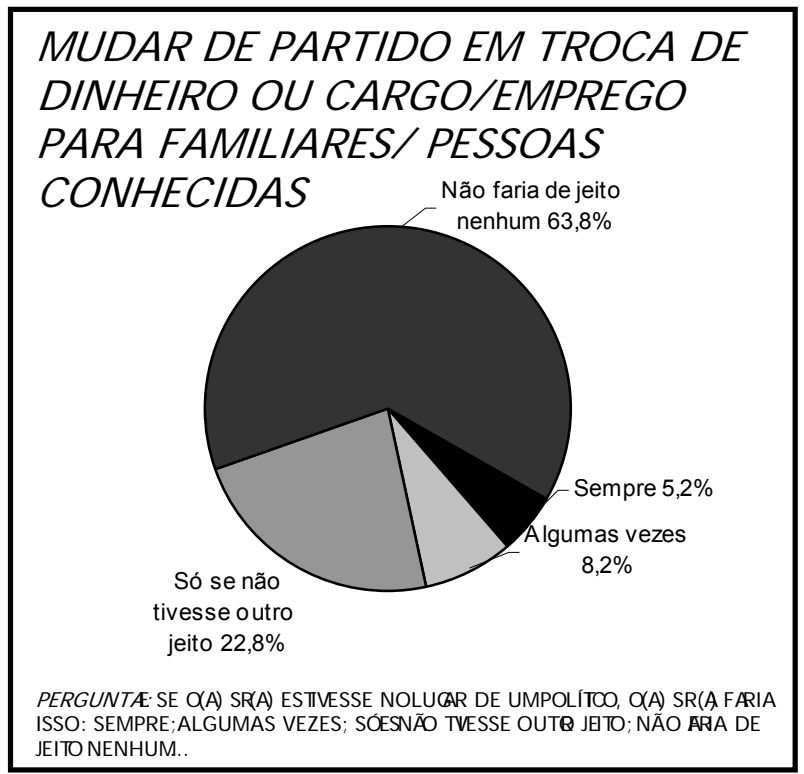

SUPERFATURAR OBRAS PÚBLICASE DESVIAR O DINHEIRO PARA O PATRIMÔNIO PESSOAL/ FAMILIARDO POLÍTICO

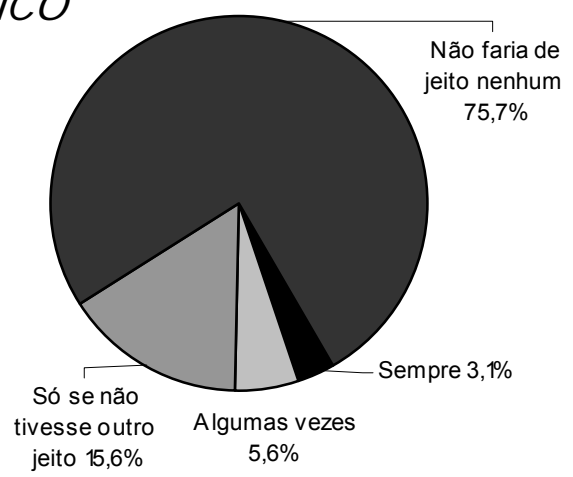

Pergunta: E se o(a) sr(a) estivesse no lugar de um político, o(a) sr(a) faria isso: sempre; algumas vezes; só se não tivesse outro jeito; não faria de ieito nenhum..

\section{USAR "CAIXA 2" EM CAMPANHAS ELEITORAIS}

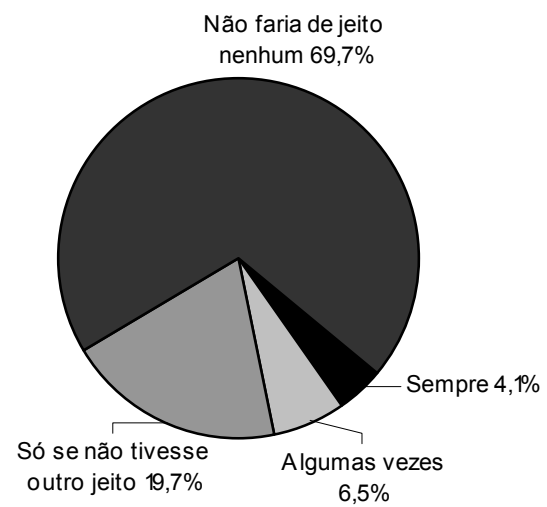

Pergunta: E se o(a) sr(a) estivesse no lugar de um político, o(a) sr(a) faria isso: sempre; algumas vezes; só se não tivesse outro jeito; não faria de ieito nenhum... 
Opiniões sobre as irregularidades

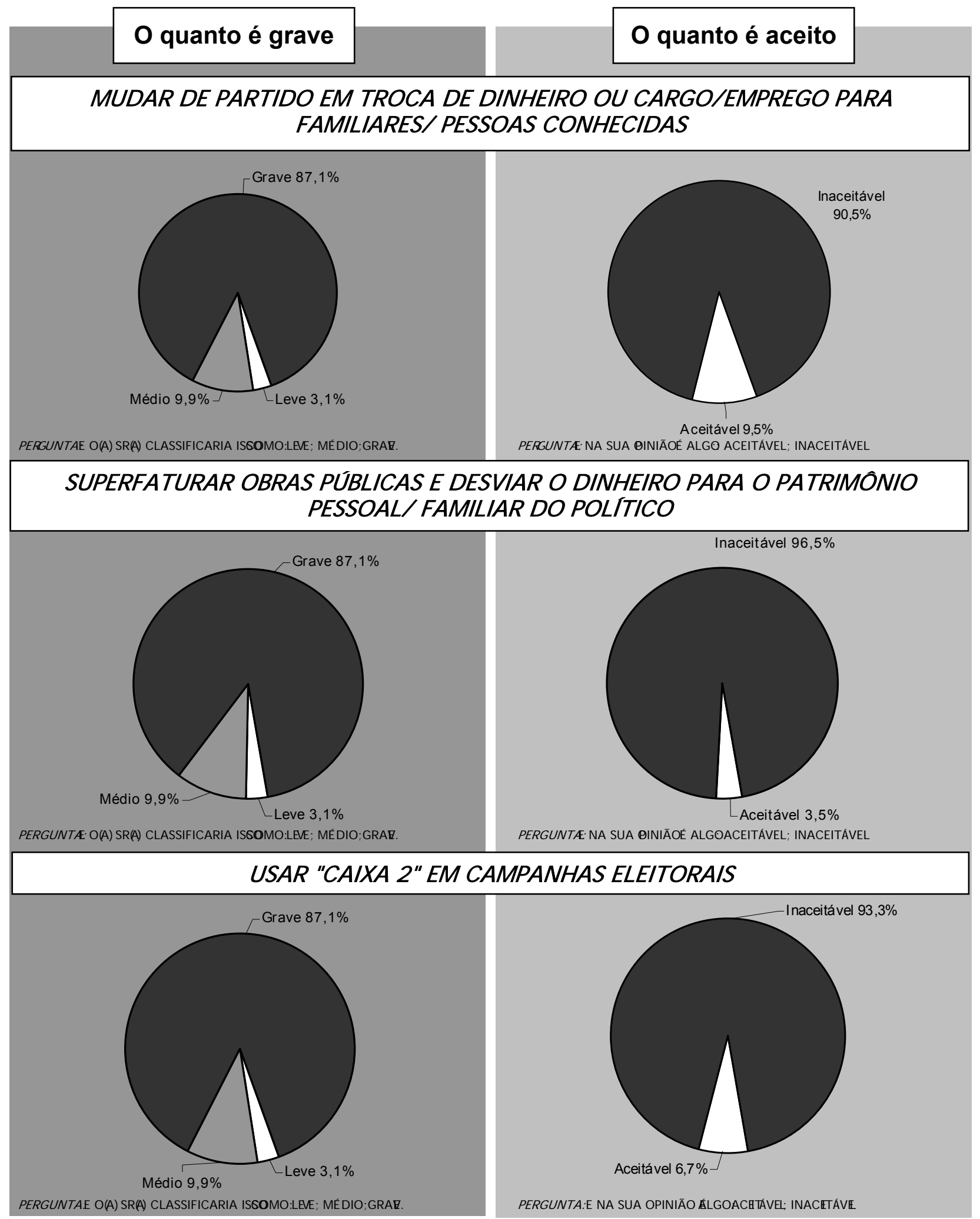

Tendências 266 OPINIÃO PÚBLICA, Campinas, Vol. 16, no 1, Junho, 2010, Encarte Tendências. p.251- 267 
